\title{
Symptom profile following cumulative mild traumatic brain injury in early adolescent rugby union players in South Africa
}

\author{
D 0 Okusanya, MSc; W J Basson, DLitt et Phil \\ Department of Psychology, Sefako Makgatho Health Sciences University, Pretoria, South Africa \\ Corresponding author: D O Okusanya (201209408@swave.smu.ac.za)
}

\begin{abstract}
Background. The symptom profiles of young adolescent rugby and non-contact sports were investigated over one sport season. Objectives. To compare the concussion symptom profiles of rugby players with those of non-contact sport players over a sport season. Methods. In a non-equivalent quasi-experimental design, a group of rugby players $(n=99)$ were compared with a demographically equivalent group of non-contact sport participants $(n=74)$. The computerised Immediate Post-concussion Assessment and Cognitive Testing (IMPACT) symptom scale was employed to evaluate and compare pre-season and post-season assessment of both groups. Results. Independent comparative analyses revealed that the damaging effects owing to exposure to concussive and sub-concussive incidents appear to be more pronounced in the rugby group in terms of symptomatic presentation compared with the controls. Conclusion. The damaging effects are compounded during a rugby season as a result of sub-concussive and concussive events.
\end{abstract}

S Afr J Child Health 2020;14(3):133-138. https://doi.org/SAJCH.2020.v14i3.1699

Rugby is a popular sport in South Africa (SA), played by children from as young as seven years of age. ${ }^{[1]}$ Rugby is classified as a high-impact and collision sport, which adds to its high potential for contact injury, such as mild traumatic brain injury (mTBI). ${ }^{[2]}$ Young players are particularly vulnerable to sustaining mTBI, as the brain is not yet fully matured and therefore more vulnerable to the effects of the damage associated with brain injury. ${ }^{[3]}$ The prevalence of $\mathrm{mTBI}$ in schoolboy rugby players has been cited to be as high as $50 \% \cdot{ }^{[4]}$ Many of these injuries are often unrecognised and unreported as players may be likely to underreport symptoms to expedite return to play. ${ }^{[5]}$ Research indicates that the younger brain is particularly vulnerable to short- and long-term effects of concussion and requires longer recovery time from symptoms, as the brain is not yet fully developed. ${ }^{[6]}$ Impulse control and selfmonitoring of behaviour are particularly susceptible to the effects of concussion during this developmental stage. ${ }^{[7]}$

While relatively few studies have been undertaken on the length of time for symptom recovery among rugby players, existing literature demonstrates that, in most cases, it is presumed that symptoms dissipate within 3 - 10 days ${ }^{[8,9]}$ However, children and adolescents may take longer to recover. ${ }^{[10]}$ Symptoms that occur within three months of the incident are considered to be 'acute'; when persisting in excess of three months, symptoms are deemed to be 'chronic.'.11] Findings by De Kruijk et al.$^{[12]}$ revealed that $28 \%$ of players had not fully recovered six months post mTBI and were therefore considered to have 'chronic' symptoms. A small minority of individuals may experience effects from six months until three years post mTBI. ${ }^{[13,14]}$ The effects of moderate to severe mTBI can be permanent, and one of the most feared long-term effects is dementia. ${ }^{[15,16]}$

Neuropsychological functional impairments following mTBI include a variety of symptoms which may significantly affect physical, cognitive and emotional well-being. ${ }^{[17-21]}$ Table 1 portrays these symptoms, of which headache, fatigue, drowsiness, nausea and sleep disturbances are among the most commonly reported symptoms following mTBI. Physical symptoms indicative of cranial nerve damage include nausea, dizziness, blurred vision, diplopia, sensitivity to light and noise, hearing loss, tinnitus, and diminished sense of taste or smell..$^{[22,23]}$ Cognitive symptoms include attention and concentration difficulties, confusion and feeling mentally 'foggy'. ${ }^{[24]}$ Behavioural and emotional symptoms include apathy and affective disturbances such as agitation, aggression, anxiety, depression, irritability and feeling more emotional. ${ }^{[25]}$

More severe injuries are regarded as 'red-flag' signs, and a longer recovery period is suggested. ${ }^{[17-21]}$ Table 2 outlines the recognised red-flag signs indicating emergency situations which necessitate referral to an emergency unit.

The short- and long-term consequences of brain concussion among young rugby players are potentially detrimental and may present a serious health risk. The present study compared the concussion symptom profiles of rugby players with non-contact sport players over a sport season.

\section{Methods}

\section{Research design and participants}

The study followed a quasi-experimental, non-equivalent design where the post-concussive symptoms of a group of rugby players $(n=143)$ were compared with a group of non-contact sport players $(n=133)$ over one sport season. A convenience sample of 276 grade 8 boys (mean age 13.5 years) was selected from two English-medium schools in KwaZulu-Natal. The groups were matched by age, years of sport participation, prior reported concussions, intelligence quotient (IQ), impulse control and neuropsychological variables (learning disabilities, anxiety, depression and attention deficit hyperactivity disorder (ADHD)). Participants were excluded if they did not participate in any sport, if they participated in other contact sport, and if they had high impulse-control scores (determined by the neurocognitive scale of the Immediate Post-concussion Assessment and Cognitive Testing (IMPACT) ) battery, low IQ (determined by 
Table 1. Common symptoms of $\mathrm{mTBI}^{\star}$

\begin{tabular}{|c|c|}
\hline Symptom & Description \\
\hline $\begin{array}{l}\text { Dizziness/ } \\
\text { vertigo }\end{array}$ & $\begin{array}{l}\text { Occurs with or withor } \\
\text { changes in position. }\end{array}$ \\
\hline Headache & $\begin{array}{l}\text { Photophobia, } \\
\text { throbbing, constant o } \\
\text { increased duration or } \\
\text { severity with increase } \\
\text { activity, sensitivity to } \\
\text { sound }\end{array}$ \\
\hline $\begin{array}{l}\text { Visual } \\
\text { disturbance }\end{array}$ & $\begin{array}{l}\text { Double vision, blurrec } \\
\text { vision }\end{array}$ \\
\hline $\begin{array}{l}\text { Nausea/ } \\
\text { vomiting }\end{array}$ & $\begin{array}{l}\text { Vomiting that occurs } \\
\text { more than twice in } \\
\text { one hour initially is a } \\
\text { red flag for increased } \\
\text { concern and may } \\
\text { necessitate a CT scan }\end{array}$ \\
\hline $\begin{array}{l}\text { Loss of } \\
\text { consciousness }\end{array}$ & $\begin{array}{l}\text { Loss of consciousness } \\
\text { for less than } 30 \\
\text { minutes }\end{array}$ \\
\hline
\end{tabular}

Fatigue or difficulty sleeping

Blacking out/ Trouble concentrating blank spells or frequent forgetfulness. Answers questions slowly or forgets the question

Emotiona disruptions, mood and personality changes

Anger and temper outburst above and beyond the child's baseline. Shorter tolerance for limit setting

Difficulty with memory

Forgetfulness or trouble understanding or accessing new or old information, trouble concentrating, confusion

\section{Comment}

Often due to acceleration/

deceleration of the brain.

Chronic headaches or

post-traumatic migraines

may develop, requiring

symptomatic treatment

Indicates increased pressure in the brain

Persistent vomiting can indicate an underlying haemorrhage and places the child at risk for dehydration, which can increase symptoms.

Loss of consciousness does not have to be present to have a brain injury and is less common in children Very common after TBI. Child should also be observed for depressive symptoms. Some children will have difficulty sleeping and develop insomnia. Lack of sleep will increase fatigue symptoms or disrupt sleep patterns

May have no memory of the injury event

Can be worse when the child is tired. May be an indication of post-traumatic seizures, requiring additional investigation with an EEG

Emotional outbursts are common and will often lessen further from the event; however, a subgroup of children may go on to have long-term personality changes.

There is often a decrease in school performance in school-age children
Table 2. Red flags indicating emergency situations*

\begin{tabular}{|c|c|}
\hline Symptom & Description \\
\hline $\begin{array}{l}\text { Loss of } \\
\text { consciousness }\end{array}$ & $\begin{array}{l}\text { Increased difficulty staying awake } \\
\text { More difficulty waking up } \\
\text { More periods of sleepiness } \\
\text { Increased confusion or agitation }\end{array}$ \\
\hline $\begin{array}{l}\text { Changes in } \\
\text { mental status }\end{array}$ & $\begin{array}{l}\text { Inability to recognise familiar people or places } \\
\text { Restlessness, aimless walking around. } \\
\text { Bizarre or unusual behaviour }\end{array}$ \\
\hline Headache & Worsening of headache; neck pain \\
\hline Changes in speech & Slurred speech \\
\hline Vomiting & $\begin{array}{l}\text { Vomiting more than twice in an hour or } \\
\text { an increase in the number of nausea and } \\
\text { vomiting episodes }\end{array}$ \\
\hline $\begin{array}{l}\text { Changes in } \\
\text { mobility }\end{array}$ & $\begin{array}{l}\text { Weakness, numbness or tingling. Imbalance, } \\
\text { falling }\end{array}$ \\
\hline Seizures & $\begin{array}{l}\text { Development or worsening of existing seizure } \\
\text { condition }\end{array}$ \\
\hline Pupil changes & $\begin{array}{l}\text { Change in pupil size - one larger than the } \\
\text { other - or rapid changes in visual disturbances }\end{array}$ \\
\hline *Adapted from Anderso & et al. $:^{[17]} \mathrm{CDC} ; ;^{[18]}$ Cohen et al. $\dot{s}^{[1] ;} ;$ Giza et al. ${ }^{[20]}$ Russo et al. ${ }^{[21]}$ \\
\hline
\end{tabular}

the experimental group and 74 non-contact sport players $(n=74)$, who made up the control group.

\section{Procedure and data collection}

Permission to conduct the study was granted by the Department of Education and the governing bodies of the schools. Participants and their parents/guardians provided written consent to take part in the study. Both the rugby group and the non-contact sport group underwent pre-season and post-season testing to compare the symptoms profiles before and at the end of the sport season.

The Post-concussion Symptom Scale Iverson, Lovell, \& Collins ${ }^{[26]}$ of the IMPACT computerised test was completed by participants to determine any post-concussive symptoms. The scale consists of 22 common mTBI symptoms as well as a symptom composite score that portrays the total average of the 22 individual symptom items. Previous similar studies reported high on reliability, internal consistency and adequate concurrent validity of the scale. ${ }^{[27-30]}$ The scale has also been validated as appropriate for English-speaking males in SA. ${ }^{[31]}$

\section{Analyses of data}

Independent $t$-test analyses of the data were done to compare the rugby group with the non-contact sport group on their reported post-concussive symptoms before and after the sport season. Independent and dependent analyses were done to compare the group means at baseline and end-of-season intervals. The repeated measures ANOVAs were used to assess the effect for the season by comparing scores for the before and end-of-season intervals.

\section{Results}

Before the sport season commenced, the rugby group obtained higher scores for 17 of the 22 individual post-concussive symptoms when compared with the non-contact sport group (Table 3). Four of the symptoms of the rugby group were significantly higher than the control group and included headache $(p=0.032)$, balance problems $(p=0.016)$, fatigue $(p=0.034)$ and concentration $(p=0.03)$. In addition, the rugby group obtained higher scores approaching the Standard Progressive Matrices), and other neuropsychological variables (measured by the neuropsychological scale of the IMPACT). The final pool of participants included 99 rugby $(n=99)$ players in

mTBI = mild traumatic brain injury; CT - computed tomography;
EEG = electroencephalogram.
${ }^{\star}$ Adapted from Anderson et al. $:{ }^{[1]]} \mathrm{CDC} ;{ }^{[18]}$ Cohen et al. $:{ }^{[19]} ;$ Giza et al. ${ }^{[20]}$ Russo et al..$[21]$ 
Table 3. Before-season comparisons of symptoms for rugby v. controls

\begin{tabular}{|c|c|c|c|c|}
\hline Baseline measures & Rugby $(n=99)$ & Controls $(n=74)$ & $t$-value & $p$-value \\
\hline Symptom composite scores ${ }^{*}$ & $10.11(11.87)$ & $7.93(10.69)$ & 1.246 & 0.108 \\
\hline Headache & $0.57(0.99)$ & $0.32(0.70)$ & 1.784 & $0.032^{\dagger}$ \\
\hline Nausea & $0.29(0.92)$ & $0.23(0.67)$ & 0.500 & 0.309 \\
\hline Vomiting & $0.22(0.74)$ & $0.11(0.42)$ & 1.193 & 0.101 \\
\hline Balance problems & $0.14(0.40)$ & $0.04(0.20)$ & 1.975 & $0.016^{\dagger}$ \\
\hline Dizziness & $0.39(0.79)$ & $0.32(0.80)$ & 0.570 & 0.285 \\
\hline Fatigue & $0.64(1.18)$ & $0.36(0.75)$ & 1.731 & $0.034^{\dagger}$ \\
\hline Trouble falling asleep & $0.79(1.31)$ & $0.57(1.23)$ & 1.123 & 0.132 \\
\hline Sleeping more & $0.38(0.87)$ & $0.57(1.43)$ & -1.511 & 0.080 \\
\hline Sleeping less & $0.74(1.31)$ & $0.76(1.51)$ & -0.090 & 0.464 \\
\hline Drowsiness & $0.49(0.97)$ & $0.39(0.93)$ & 0.701 & 0.242 \\
\hline Sensitivity to light & $0.47(0.91)$ & $0.32(1.04)$ & 1.015 & 0.156 \\
\hline Sensitivity to noise & $0.25(0.73)$ & $0.26(0.89)$ & -0.034 & 0.487 \\
\hline Irritability & $0.72(0.98)$ & $0.77(1.37)$ & -0.297 & 0.384 \\
\hline Sadness & $0.26(0.76)$ & $0.27(0.73)$ & -0.132 & 0.448 \\
\hline Nervousness & $0.62(1.06)$ & $0.50(0.91)$ & 0.758 & 0.225 \\
\hline Emotional & $0.32(0.73)$ & $0.19(0.54)$ & 1.264 & 0.095 \\
\hline Numbness & $0.25(0.76)$ & $0.12(0.45)$ & 1.326 & 0.078 \\
\hline Slowed down & $0.43(0.88)$ & $0.38(0.86)$ & 0.418 & 0.338 \\
\hline Mentally foggy & $0.26(0.75)$ & $0.11(0.65)$ & 1.415 & 0.076 \\
\hline Concentration & $0.78(1.08)$ & $0.47(0.98)$ & 1.904 & $0.030^{\dagger}$ \\
\hline Remembering & $0.72(0.94)$ & $0.50(0.88)$ & 1.548 & 0.062 \\
\hline Visual problems & $0.36(0.96)$ & $0.27(0.94)$ & 0.637 & 0.263 \\
\hline
\end{tabular}

significance for a further four symptoms: emotional ( $p=0.095)$, numbness $(p=0.078)$, mentally foggy $(p=0.076)$ and remembering $(p=0.062)$. The symptom composite score (sum of the 22 individual items) for the rugby group was higher, although not significantly (10.11), when compared with the control group (7.93), $(p=0.108)$.

The symptom composite score (sum of 22 items) for both groups increased after the sport season. A more robust increase in symptom reports is seen for the rugby group (10.24 to 13.64) when compared with the non-contact sport group (9.46 to 9.68), as illustrated in Fig. 1.

Dependent $t$-test comparisons of the groups before $\mathrm{v}$. end of season revealed the following significant findings (Table 4). The rugby group reported higher scores on a total of 19 individual symptom measures at end of season when compared with their pre-season results. Of these, three symptoms were significantly higher, namely balance problems $(p=0.005)$, fatigue $(p=0.016)$ and mentally foggy ( $p=0.013)$. Seven symptoms approached significance: sleeping more $(p=0.067)$, drowsiness $(p=0.062)$, sensitivity to noise ( $p=0.043)$, irritability $(p=0.041)$, slowed down $(p=0.041)$, difficulty concentrating ( $p=0.061)$ and difficulty remembering $(p=0.088)$. The symptom composite score also approached a significantly higher score at end of season $(p=0.037)$.

The control group reported slightly higher scores on a total of 15 individual symptoms at end of season compared with their preseason results, although only two scores were significant, namely an increase in balance problems $(p=0.020)$ and sleeping more $(p=0.017)$. The control group reported lowered scores for two symptom measures at the end-of-season interval, namely sleeping less $(p=0.036)$ and irritability $(p=0.030)$.

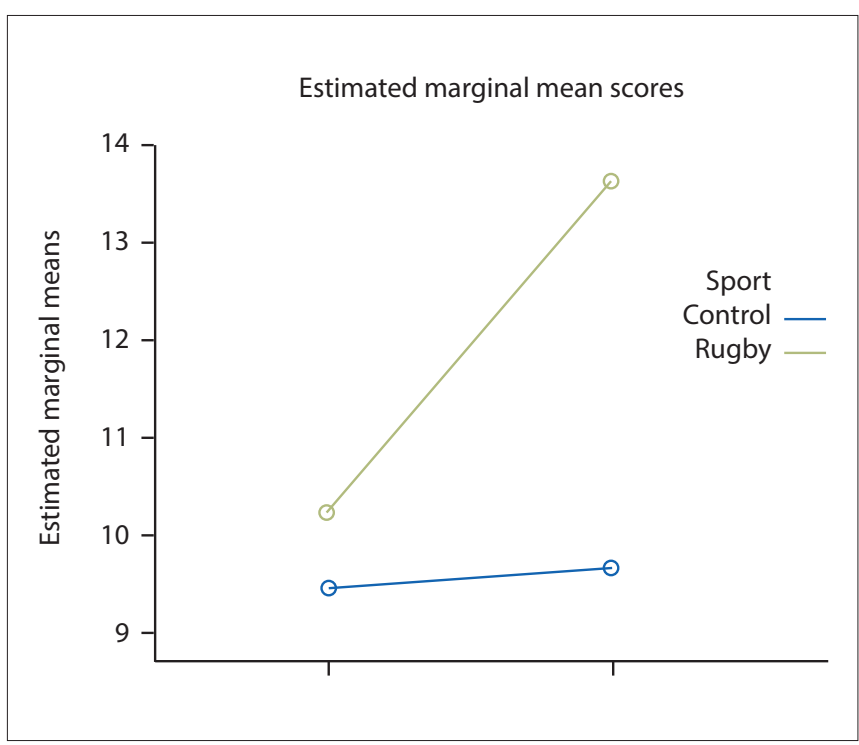

Fig. 1. Before v. end of season symptom composite scores.

\section{Discussion}

The purpose of this study was to compare the mTBI symptom profiles of young rugby players with non-contact sport players. The results indicate that exposure to concussive and sub-concussive events during a sport season seemed to have had a more detrimental effect on the rugby players than on the non-contact sport participants. Furthermore, all the significant results and trends are predominantly in the direction of a worsening of symptom reporting among the rugby group post season. 
Table 4. Before v. end of season comparisons of symptoms for rugby and controls

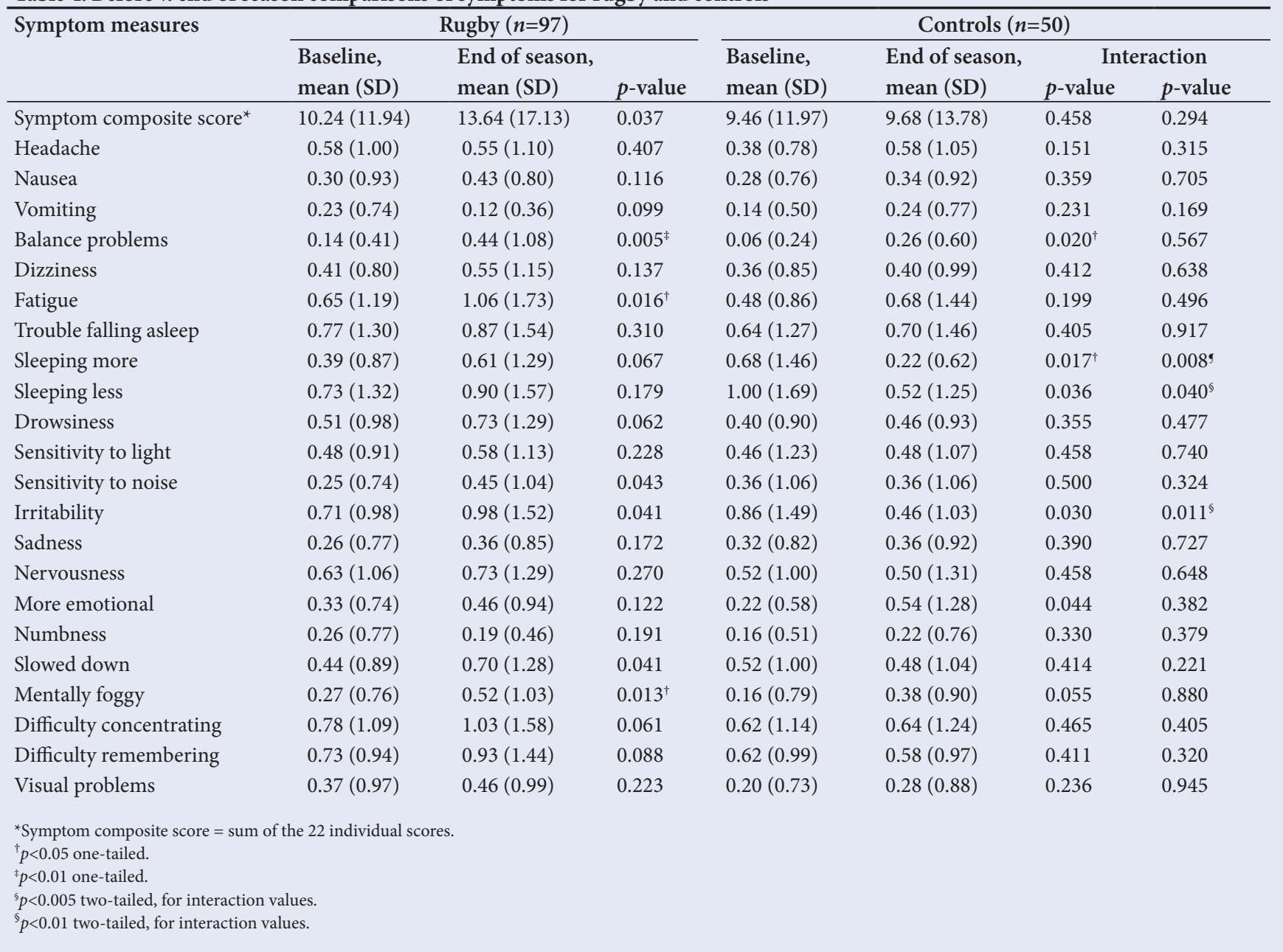

The after-season results are in line with research conducted in SA by Shuttleworth-Edwards et al. ${ }^{[32]}$ who found that schoolboy rugby players reported significantly more post-concussive symptoms relative to the controls (non-contact sport players) after the sport season. As in the present study, the Shuttleworth-Edwards ${ }^{[32]}$ study found the most frequently reported symptoms to include headache, fatigue, balance problems, concentration, dizziness, light sensitivity and sleeping problems. These findings are in line with international research studies by Brooks et al.; ${ }^{[2]}$ Kearney et al. ${ }^{[4]}$ Marar et al..$^{[33]}$ and Green et al. ${ }^{[34]}$ which showed that at three months post injury, high school athletes were still reporting more symptoms of headache, dizziness and poor concentration compared with controls, illustrating prolonged effects in high school athletes. These persisting symptoms could have severe effects on an individual's daily activities, including ability to work and attend school, function independently at home, or develop and maintain appropriate social relations. ${ }^{[35]}$ Furthermore, the danger of multiple concussions may be cumulative even when the concussive blows are relatively minor. Returning to play while still symptomatic has many problematic consequences, such as second-impact syndrome (SIS) which can be fatal. SIS is a rare condition where a seemingly mild blow to the previously concussed head may result in massive brain swelling, increased intracranial pressure and brain herniation. ${ }^{[36,37]}$ SIS usually occurs in adolescents of $14-16$ years of age.
Luna and Sweeney ${ }^{[38]}$ describe adolescence as a period of 'transition to efficient brain collaboration'; executive circuits become more refined and better connected, and therefore more efficient and effective in organising and monitoring behaviour. Consequently, damage to the young developing brain can be detrimental to cognitive, executive and socio-emotional functioning and subsequent academic and social attainment. Hence, returning an athlete to participation prior to complete recovery from mTBI may greatly increase the risk of lingering, long-term or catastrophic neurological sequelae. ${ }^{[35]}$

Although the incidence of child and adolescent rugby concussions has been reported to range from $0.2-6.9$ concussions per 1000 player hours, ${ }^{[4]}$ these figures are said to be much lower than reality. The discrepancy is due to the difficulty in making a diagnosis, lack of knowledge by players and coaches, and underreporting. Underreporting happens because players and coaches do not wish players to be taken out of play. Fewer than $50 \%$ of coaches recognised the increased risk of suffering a second concussion if a player returned to play before the first concussion had fully healed. ${ }^{[4]}$ Furthermore, 25\% of players in New Zealand believed they had to lose consciousness for the injury to be classified as concussion. Matheson et al.$^{[5]}$ suggest that the decision to return to play should be made by an independent neurologist or sport physician who has no particular interest in approving a premature return to play, thus preventing players and coaches from putting pressure on the team doctor. 
The present study employed a quasi-experimental cross-sectional design of which the outcomes could be the result of pre-existing differences. Therefore, attempts were made to match the comparative groups as closely as possible on extraneous variables. Groups were statistically equivalent for gender, age, level of education, estimated IQ and years of sport participation.

The study did not distinguish between general and red flag mTBI symptoms reported by participants. It would be advisable for future studies to make this distinction, as red flag symptoms require immediate medical intervention.

Furthermore, information on the time period that mTBI symptoms were present was not required. It is recommended that future studies obtain this information, as continuous play with chronic mTBI symptoms may be detrimental to the health of contact sports players.

It is quite feasible that there could be differences in motivation between the controls and the rugby players, particularly those keen to continue with sports participation. Therefore, it might be considered a limitation if significant findings or a lack thereof may have been due to participants' fatigue or lack of motivation. ${ }^{[39]}$

\section{Conclusion}

The findings of the present study provide fairly persuasive evidence that male high school rugby players, in comparison with non-contact sport players, experience adverse symptomatic presentation as a result of contact sport participation. These effects are compounded during a rugby season as a result of sub-concussive and concussive events. Therefore, public awareness of the neuropsychological damage incurred from concussive and sub-concussive events in contact sport at high school level should be promoted to ensure timeous identification of cerebrally compromised players to facilitate appropriate medical and neuropsychological management.

\section{Declaration. None.}

Acknowledgments. None.

Author contributions. DOO and WJB contributed equally to conceiving and writing the paper.

Funding. None.

Conflicts of interest. None.

1. Mc Fie S, Brown J, Hendricks $S$, et al. Incidence and factors associated with concussion injuries at the 2011 to 2014 South African Rugby Union Youth Week Tournaments. Clin J Sport Med 2016;26(5):398-404. https://doi.org/10.1097/ jsm.0000000000000276

2. Brooks J, Kemp S, Newth A, Sylvester R. Managing recovery from concussion. BMJ 2016;355. https://doi.org/10.1136/bmj.i5629

3. McIntosh AS, McCrory P, Finch CF, Wolfe R. Head, face and neck injury in youth rugby: Incidence and risk factors. Br J Sports Med 2010;44(3):188-193. https://doi.org/10.1136/bjsm.2007.041400

4. Kearney PE, See J. Misunderstandings of concussion within a youth rugby population. J Sci Med Sport 2017;20(11):981-985. https://doi.org/10.1016/j. jsams.2017.04.019

5. Matheson GO, Shultz R, Bido J, Mitten MJ, Meeuwisse WH, Shrier I. Returnto-play decisions: Are they the team physician's responsibility? Clin J Sport Med 2011;21(1):25-30. https://doi.org/10.1097/jsm.0b013e3182095f92

6. Semrud-Clikeman M, Klipfel KM. TBI and concussions in student athletes: How do severity of injury, age, and gender influence recovery. J Pediatr Neuropsychol 2016;21;2(1-2):58-69. https://doi.org/10.1007/s40817-015-0010-8

7. Baron IS. Maturation into impairment: The merit of delayed settlement of pediatric forensic neuropsychology cases. In: Heilbronner RL (editor). Neuropsychology in the Courtroom: Expert Analysis of Reports and Testimony. New York: Guilford Press, 2008:66-78.

8. Broglio SP, Ferrara MS, Macciocchi SN, Baumgartner TA, Elliott R. Test-retest reliability of computerized concussion assessment programs. J Athl Train 2007;42(4):509-514. https://doi.org/10.1249/01.mss.0000320764.14496.bf

9. Collie A, Makdissi M, Maruff P, Bennell K, McCrory P. Cognition in the days following concussion: comparison of symptomatic versus asymptomatic athletes. J Neurol Neurosurg Psychiatry 2005;37:S276. https://doi. org/10.1097/00005768-200505001-01419
10. Halstead ME, Walter KD. Sport-related concussion in children and adolescents. Pediatrics 2010;126(3):597-615. https://doi.org/10.1542/peds.2010-2005

11. Blennow K, Brody D, Kochanek P, et al. Traumatic brain injuries. Nat Rev Dis Primers 2016;17(2):16084. https://doi.org/10.1038/nrdp.2016.84

12. De Kruijk JR, Leffers P, Menheere PP, Meerhoff S, Rutten J, Twijnstra A. Prediction of post-traumatic complaints after mild traumatic brain injury: Early symptoms and biochemical markers. J Neurol Neurosurg Psychiatry 2002;73:727-732. https://doi.org/10.1136/jnnp.73.6.727

13. Management of concussion/mTBI working group. VA/DoD clinical practice guideline for management of concussion/mild traumatic brain injury. J Rehabil Res Dev 2009;46(6):CP1-68. https://doi.org/10.1037/e570732010-001

14. Kontos AP, Collins M, Russo SA. An introduction to sports concussion for the sport psychology consultant. J Appl Sport Psychol 2004;16(3):220-235. https:// doi.org/10.1080/10413200490485568

15. Nordström A, Nordström P. Traumatic brain injury and the risk of dementia diagnosis: A nationwide cohort study. PLoS Med 2018;15(1). https://doi. org/10.1371/journal.pmed.1002496

16. Ramalho J, Castillo M. Dementia resulting from traumatic brain injury. Dement Neuropsychol 2015;9(4):356-368. https://doi.org/10.1590/198057642015 dn 94000356

17. Anderson T, Heitger M, Macleod AD. Concussion and mild head injury. Practical Neurology BMJ 2006;6(6):342-357. https://doi.org/10.1136/ jnnp.2006.106583

18. Centers for Disease Control and Prevention (CDC). Guide to Writing about Traumatic Brain Injury in News and Social Media. Atlanta, GA: National Center for Injury Prevention and Control, Division of Unintentional Injury Prevention. 2015. http://www.cdc.gov/traumaticbraininjury/get_the_facts. html (accessed 15 October 2015).

19. Cohen JS, Gioia G, Atabaki S, Teach SJ. Sports-related concussions in paediatrics. Curr Opin Pediatr 2009;21(3):288-293. https://doi.org/10.1097/ mop.0b013e32832b1195

20. Giza CC, Kutcher JS, Ashwal S, et al. Summary of evidence-based guideline update: Evaluation and management of concussion in sports: Report of the Guideline Development Subcommittee of the American Academy of Neurology. Neurology 2013;80(24):2250-2257. https://doi.org/10.1212/ wnl.0b013e31828d57dd

21. Buzzini SR, Guskiewicz KM. Sport-related concussion in the young athlete. Curr Opin Pediatr 2006;18(4):376-382. https://doi.org/10.1097/01. mop.0000236385.26284.ec

22. Legome E, Alt R, Wu T. Postconcussive syndrome. 2009. eMedicine from WebMD. http://emedicine.medscape.com/article/828904-overview (accessed 2 February 2010).

23. Rios JS. Traumatic brain injury in contact sports (doctoral dissertation). Dept of Psychology, School of Medicine, Boston University; 2014.

24. Fazio VC, Lovell MR, Pardini JE, Collins MW. The relation between post concussion symptoms and neurocognitive performance in concussed athletes. Neuro Rehabilitation 2007;22(3):207-216. https://doi.org/10.3233/nre-2007-22307

25. Arciniegas DB, Anderson CA, Topkoff J, McAllister TW. Mild traumatic brain injury: A neuropsychiatric approach to diagnosis, evaluation, and treatment. Neuropsychiatr Dis Treat 2005;1(4):311-327.

26. Iverson GL, Lovell MR, Collins MW. Interpreting change on ImPACT following sport concussion. Clin Neuropsychol 2003;17(4):460-467. https:// doi.org/10.1076/clin.17.4.460.27934

27. Iverson GL, Lovell MR, Collins MW. Validity of ImPACT for measuring processing speed following sports-related concussion. J Clin Exp Neuropsychol 2005;27(6):683-689. https://doi.org/10.1081/13803390490918435

28. Schatz P, Pardini JE, Lovell MR, Collins MW, Podell K. Sensitivity and specificity of the ImPACT Test Battery for concussion in athletes. Arch Clin Neuropsychol 2006;21(1):91-99. https://doi.org/10.1016/j.acn.2005.08.001

29. Ellemberg D, Henry LC, Macciocchi SN, Guskiewicz KM, Broglio SP. Advances in sport concussion assessment: from behavioral to brain imaging measures. J Neurotrauma 2009;26(12):2365-2382. https://doi.org/10.1089/neu.2009.0906

30. Iverson GL, Lovell MR, Collins, MW. Normative data: For Foxpro (Original Platform) version of ImPACT 2003. http://impacttest.com/publications/ baseline_data/normative (accessed 23 October 2010).

31. Shuttleworth-Edwards AB, Whitefield-Alexander VJ, Radloff SE, et al. Computerized neuropsychological profiles of South African versus US athletes: A basis for commentary on cross-cultural norming issues in the sports concussion arena. Phys Sportsmed 2009;37(4):45-52. https://doi.org/10.3810/ psm.2009.12.1741

32. Shuttleworth-Edwards AB, Kemp RD, Rust AL, Muirhead JG, Hartman NP, Radloff SE. Cross-cultural effects on IQ test performance: A review and preliminary normative indications on WAIS-III test performance. J Clin Exp Neuropsychol 2004;26(7):903-920. https://doi. org/10.1080/13803390490510824

33. Marar M, McIlvain NM, Fields SK, Comstock RD. Epidemiology of concussions among United States high school athletes in 20 sports. Am J Sports Med 2012;40(4):747-755. https://doi.org/10.1177/0363546511435626

34. Green MF, Kern RS, Braff DL, Mintz J. Neurocognitive deficits and functional outcome in schizophrenia: Are we measuring the 'right stuff'? Schizophr Bull 2000;26(1):119-136. https://doi.org/10.1093/oxfordjournals.schbul.a033430

35. Webbe F, Lovell MR, Ruben J, Echemendia JT, et al. Traumatic brain injury in sports: International neuropsychological perspective. Arch Clin Neuropsychol 2004;19(8):1111-1113. https://doi.org/10.1016/j.acn.2004.05.002 
36. Cantu RC. Recurrent athletic head injury: Risks and when to retire. Clin Sports Med 2003;22(3):593-603. https://doi.org/10.1016/s0278-5919(02)00095-9

37. Schunk JE, Schutzman SA. Pediatric head injury. Pediatr Rev 2012;33(9):398411. https://doi.org/10.1542/pir.33-9-398

38. Luna B, Sweeney JA. The emergence of collaborative brain function: fMRI studies of the development of response inhibition. Ann NY Acad Sci 2004;1021(1):296-309. https://doi.org/10.1196/annals.1308.035
39. Clark SB. Neurocognitive and symptom profiles of concussed and nonconcussed provincial rugby players over one season (doctoral dissertation). Dept of Psychology, Rhodes University, Grahamstown; 2011.

Accepted 27 February 2020 